\title{
Journal of Surgery
}

[Jurnalul de Chirurgie]

\section{Gastrointestinal stromal tumor}

Mihaela Dranga ${ }^{1,2}$, Catalina Mihai ${ }^{1,2}$, Cristina Cijevschi' ${ }^{2}$, Iulian Bejinariu' ${ }^{2}$, Andrei Andronic ${ }^{2}$, Otilia Gavrilescu ${ }^{1,2}$

UUniversitatea de Medicina și Farmacie „Grigore T. Popa”, Iași, ${ }^{2}$ Institutul de Gastroenterologie si Hepatologie, Sp.Sf.Spiridon

\begin{abstract}
Stromal tumors are the most common mesenchymal tumors in the digestive tract. Epidemiological data have shown an incidence of 11-20 per million people, the average age of diagnosis being 58 years. The location of these tumors can be anywhere on the gastrointestinal tract. The positive diagnosis is established by histopathological and immunohistochemical examination. The evolution of patients is correlated with the size of the initial tumor, the mitotic index and the topographic location. We present the case of a patient with an old anemic syndrome, considered deficiency anemia, with multiple hospitalizations, without response to substitution therapy that suddenly developed ascites. CT scan of the abdomen revealed a large abdominal tumor with jejunal origin. The positive diagnosis was established postoperatively by correlating the histopathological aspects with the immunohistochemical tests. The postoperative evolution was marked by complications, and one week later, the patient died secondary to a jejuno-colic fistula.
\end{abstract}

Keywords: Stromal tumors, histopathological aspects, immunohistochemical tests

\section{Introducere}

Tumorile gastrointestinale stromale (GIST) reprezintă un grup heterogen de tumori mezenchimale rare cu evoluţie malignă impredictibilă $(3 \%)$ (1). Acestea sunt totuşi cele mai frecvente tumori mezenchimale ale tractului digestiv. Definirea originii lor în celulele interstitiale mezenchimale Cajal şi a particularităţilor morfologice şi clinico-evolutive permite clasificarea acestora ca entitate distinctă. Se dezvoltă la nivelul întregului tubul digestiv de obicei extraluminal (2). Prezentăm cazul unui pacient cu un vechi sindom anemic, interpretat ca anemie carenţială, cu multiple spitalizări, fără răspuns la terapia de substituţie care dezvoltă brusc ascită. Examinarea prin computer tomografia abdominală evidenţiază o tumoră abdominală de mari dimensiuni cu dezvoltare intestinală. Diagnosticul de certitudine este stabilit postoperator prin corelarea aspectelor histopatologice cu testele imunohistochimie. Evoluţia postoperatorie a fost marcată de complicaţii, iar la o săptămână, pacientul a decedat secundar unei fistule jejuno-colice.

\section{Prezentare caz}

Prezentăm cazul unui pacient în vârstă de 68 ani care a fost dirijat din teritoriu în Institutul de Gastroenterologie şi Hepatologie Iaşi pentru investigarea unui sindrom ascito-edematos relativ brusc instalat în urmă cu cinci săptămâni, însoţit de scădere ponderală importantă şi astenie fizică marcată.

Pacientul menţionează în urmă cu 6 ani un episod de hemoragie digestivă superioară, exteriorizat prin melenă. Investigaţiile endoscopice efectuate la acea dată, nu au evidenţiat leziuni cu potenţial

Corresponding author:, Cătălina Mihai, e-mail:
catalinamihai@yahoo.com

Received: April 19, 2021; Accepted: May 28, 2021;Published June, 29,2021

Citation:. Dranga Mihaela, Mihai Cătălina, Cijevschi Cristina, Bejinariu I., Andronic A. Gavrilescu Otilia. Gastrointestinal stromal tumor. Journal of Surgery [Jurnalul de chirurgie]. 2021; 17(2): $127-131$, [Article in Romanian]. DOI: 10.7438/JSURG.2021.02.07

Copyright: ( 2021 Dranga Mihaela et al. This is an open-access article distributed under the terms of the Creative Commons Attribution License, which permits unrestricted use, distribution, and reproduction in any medium, provided the original author and source are credited 
hemoragic. Sângerarea a fost considerată secundară unei gastrite drog-induse autolimitate.

În perioada 2018-2019, pacientul este luat în evidenţă hematologică teritorial cu anemie pluricarenţială, cu spitalizari multiple pentru anemie severă, cu răspuns parţial la transfuzii şi tratament marțial administrat atât intraspitalicesc cât şi la domiciliu.

La ultima internare teritorială pacientul s-a prezentat cu ascită în cantitate medie, relativ brusc instalată în ultima lună şi tromboflebită superficială membrul inferior drept, fiind dirijat teritorial în Secţia de Medicină Internă. Clisma baritată a evidenţiat cec neomogen opacifiat. Examinarea prin computer tomografie abdomino-pelvină infirmă afectarea cecală. În plus, nu au fost evidențiate modificări imagistice pentru stabilirea etiologiei ascitei. Pacientul este dirijat la Institutul de Gastroenterologie şi Hepatoogie, Iaşi pentru continuarea investigaţiilor şi stabilirea contuitei terapeutice.

La internare pacientul prezintă stare generală influenţată, abdomen mult mărit de volum cu circulaţie colaterală şi matitate la percuţie deplasabilă pe flancuri şi semne clinice ale sindromului anemic: paloare sclerotegumentară, platonichie, tahicardie (FC $=100 / \mathrm{min}$ ).

Hematologic este reconfirmată anemia $(\mathrm{Hb}=$ $10 \mathrm{~g} / \mathrm{dl}, \quad \mathrm{Ht}=34,9 \%$ ), cu caracter microcitar (VEM=62,7 fL, CHEM= 28,7 g/dl, HEM=18 pg/cell), hiposideremică (Fe seric $20 \gamma \%$ ) prin pierdere cronică (feritina $0 \mathrm{ng} / \mathrm{dL}$ ). În plus, leucocitoză importantă $(32.700 / \mu 1) \mathrm{cu}$ neutrofilie $(87,6 \%$ \%) şi trombocitoză $(468.000 / \mu 1)$.

Tabloul biochimic evidențiază colestază anicterică $(\mathrm{FA}=255,31 \mathrm{U} / \mathrm{L}, \mathrm{GGT}=91,6 \mathrm{U} / \mathrm{L}$, bilirubina normală), hipoproteinemie (proteine totale $6,4 \mathrm{mg} / \mathrm{dl}) \quad \mathrm{cu}$ hipoalbuminemie $(44,1 \%)$ şi hipergammaglobulinemie $(30,3 \%)$ şi modificarea probelor de coagulare (indice Quick 64\%).

Paracenteza exploratorie nu aduce informaţii suplimentare privind etiologia ascitei. Lichidul peritoneal are aspect serocitrin, cu reacţia Rivalta negativă (transudat) cu celularitate scăzută (630/mmc), fără modificări biochimice şi culturi negative.

În condiţiile leucocitozei şi a trombocitozei importante se ridică suspiciunea unei ocluzii secundare a fluxului venos abdominal prin tromboze având ca substrat un sindrom mieloproliferativ. Consultul hematologic interpretează proliferarea ca reactivă la pierderea cronică de sânge, diagnostic susţinut şi de frotiul periferic în limite normale.

Ecografia abdominală nu a fost concludentă datorită lichidul de ascită în cantitate mare care a împidicat examinarea. Ecografic se descrie un ficat hiperecogen, cu dimensiuni crescute, neomogen, colecist cu pereţi colesterolotici care conţine o imagine hiperreflectogenă, cu con de umbră posterior, sugestivă pentru litiază biliară veziculară, splina omogenă, cu dimensiuni normale. În hemiabdomenul drept apare o zonă neomogenă imprecis delimitată de 135-94 mm care nu poate fi încadrată (tumoră?, ascită cloazonată?, abces?) (Fig. 1).

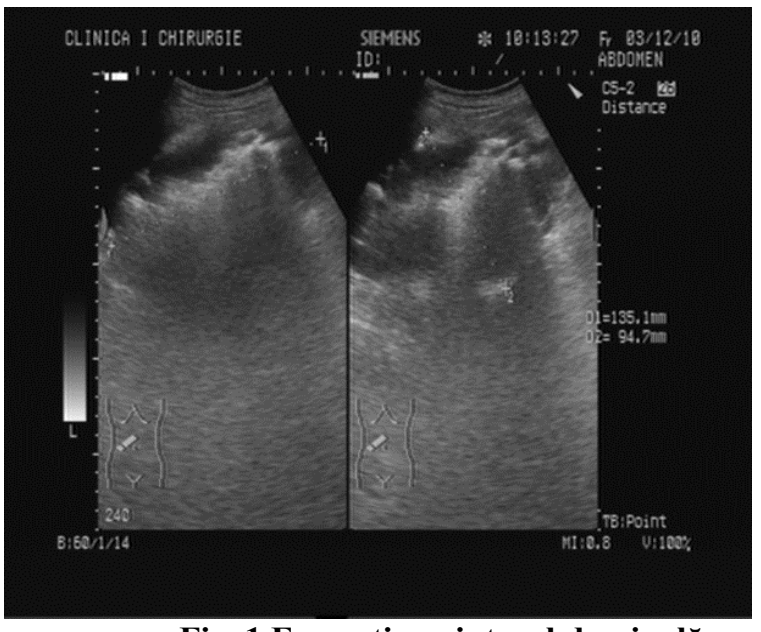

Fig. 1 Formaţiune intraabdominală evidenţiată la ecografia abdominală

Pentru precizare diagnostică se decide repetarea CT-ului abdomino-pelvin. Acesta evidenţiază în hemiabdomenul drept, inframezocolic formaţiune expansivă cu apartenenţă (sau invazie) la o ansă jejunală, dezvoltată predominant extraparietal, necrozată şi ulcerată(GIST? Schwanom? tumoră peritoneală cu invazie jejunală?). Ficatul prezinta dimensiuni crescute, cu arii hipodense suggestive pentru infarcte hepatice.; stenoze semnificative prin aterom necalcificat, ale mezentericei superioare şi arterei hepatice commune la origine. Se evidenţiază ascită în cantitate medie-mare, litiază veziculară, pancreas lipomatos şi artroză vertebrală şi sacro-iliacă dreaptă (Fig. 2).

$\mathrm{Cu}$ diagnosticul de tumoră abdominală pe segmentul jejunal se intervine chirurgical, intraoperator descoperindu-se o tumorã de 15/15/8 cm dezvoltată la $12 \mathrm{~cm}$ de valva ileo-cecală, la nivelul ileonului.

Examenul histopatologic al piesei de rezecție descrie macroscopic piesa de hemicolectomie dreaptă cu ileon de $22 \mathrm{~cm}$ şi colon de $33 \mathrm{~cm}$. La $12 \mathrm{~cm}$ de valva ileocecală, formaţiune tumorală, situată în subseroasă, cu extensie în mezoul intestinului subţire, cu prindere de fragmente intestinale, cu suprafaţa boselată şi posibile zone de ruptură. 


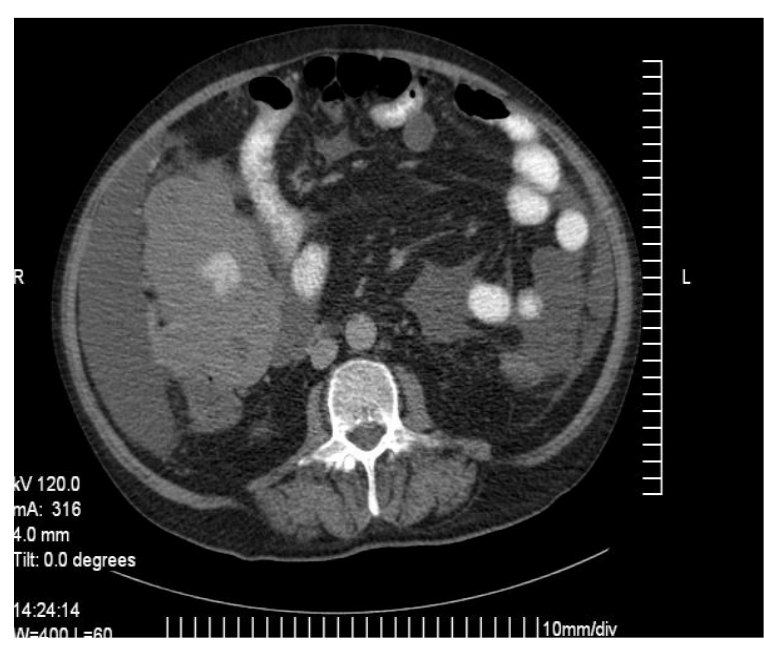

Fig. 2 Examen computer tomograf abdominopelvin

Aspectul microscopic este proliferare celulară de tip conjunctiv cu arhitectura fasciculată, cu fascicule orientate în direcţii variate, pleiomorfism citonuclear redus şi fără mitoze evidente. Se mai remarcă izolate focare de necroză şi arii de hemoragie recentă. Marginile de rezecţie ai limfoganglionii regionali recoltaţi (nr. 17) prezintã arhitectura conservatã, unii cu marcată histiocitoză sinusală, fără aspecte tumorale (Fig. 3).

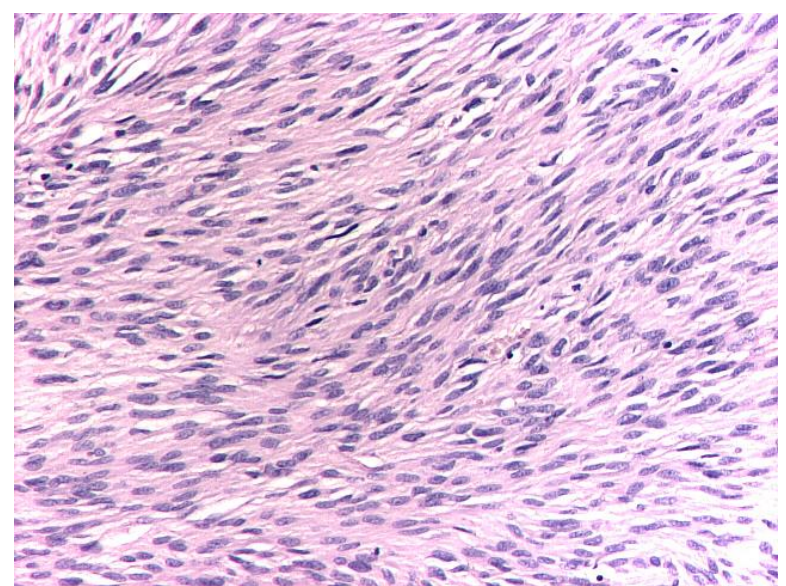

Fig.3. HE.,ob x 10,proliferare celulară, fusiformă, fasciculată, organizată

Având în vedere aspectul histopatologic la coloraţiile uzuale, sugestiv pentru o tumorã gastrointestinală stromală, se recomandã teste imunohistochimice pentru confirmarea diagnosticului. Acestea evidenţiazã: Desmin negativ în celulele tumorale, pozitiv în musculara proprie restantă, CD 34 intens pozitiv zonal, CD 117 moderat pozitiv difuz în celulele tumorale S100 negativ în tumoră, pozitiv în plexul submucos (Fig. 4), Ki67 pozitiv în foarte rari nuclei (sub 2\%), confirmând diagnosticul de TGIS cu localizare intestinalã (Fig. 5).

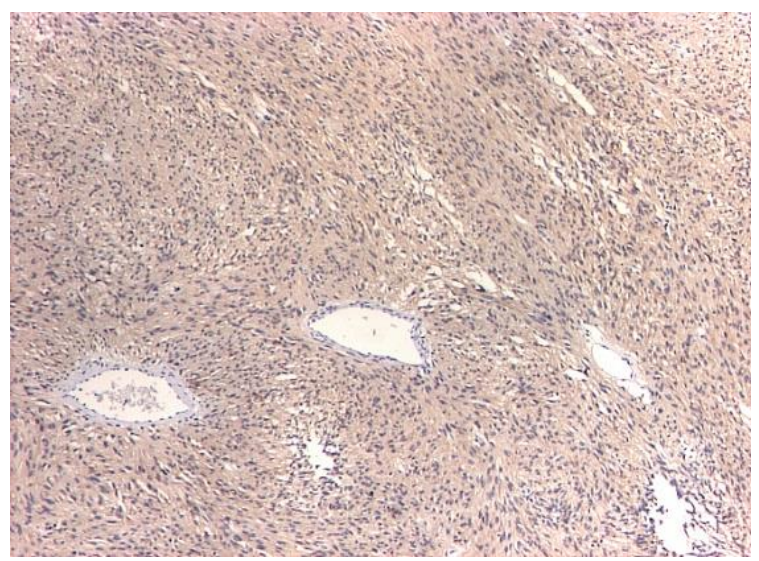

Fig. 4. CD117 moderat pozitiv difuz

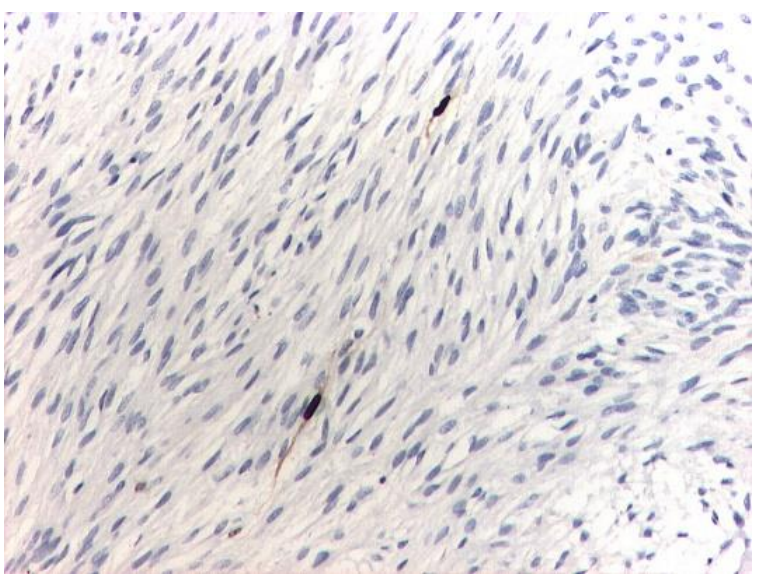

Fig.5. Ki67-pozitiv in foarte rari nuclei(sub 2\%)

Pe baza rezultatului histopatologic s-a efectuat încadrarea TGIS în grupul cu risc înalt de evoluţie malignã conform clasificãrii Fletcher.

Evoluţia postoperatorie este marcată de complicaţii, la o saptamână postoperator pacientul devine febril. Examinările imagistice evidenţiază fistulă jejuno-colică pentru care s-a reintervenit operator, pacientul decedând la mai puţin de 24 ore postoperator în condiţiile stării generale grave şi a malnutriţiei severe anterioare operaţiei.

\section{Discuţii}

Termenul de GIST a fost introdus pentru prima oarã în anul1983 de Mazur şi Clark (3). În 
aceastã categorie au fost cuprinse un grup heterogen de tumori mezenchimale cu grade variate de diferenţiere, de tip fuziform sau epiteloid . Tumorile stromale, deși rare, dar sunt cele mai frecvente tumori de origine mezenchimală de la nivelul tubului digestiv. Studii populaţionale au evidenţiat o incidenţă de 11-20 la un milion de persoane, vârsta medie fiind de 58 de ani (4).

Localizarea acestor tumori poate fi pe întreg tractul gastrointestinal . In ordinea frecvenţei ele apar pe stomac $55 \%$, duoden şi intestin subţire $30 \%$, esofag $5 \%$, rect $5 \%$, colon $2 \%(5)$. Excepţional, pot fi întâlnite în colecist, apendice, marele epiploon sau mezenter (5). În localizarea la nivelul intestinului subţire diagnosticul este relativ dificil, tumora oferind semne clinice doar în stadiul de complicaţii de tip hemoragic sau ocluziv. În afara acestora diagnosticul este accidental cu ocazia unei laparotomii sau laparoscopii efectuate pentru altă suspiciune diagnosticã.Computer tomografia, echografia sau arteriografia evidenţiază tumora dar fără a-i putea preciza natura (6).

Certitudinea diagnosticului o conferã examenul histopatologic şi imunohistochimic. Acesta din urmă determinã markerii specifici tumorali de tipul: c-KIT (glicoproteină din grupa receptorilor tyrozin-kinazici, cu pozitivitate în $95 \%$ din cazurile cu GIST), CD 34 (marker specific al celulei mezenchimale, pozitiv în $70 \%$ din cazurile cu GIST), actina specificã muşchiului neted, proteina S-100, desmina şi Ki67(marker al proliferării celulare care oferă date prognostice şi este util în monitorizarea pacienţilor (7).

Evoluţia pacienţilor cu GIST este corelatã cu dimensiunile tumorii iniţiale, indicele mitotic şi localizarea topograficã (8). Astfel, o tumorã stromală a stomacului are un prognostic mai bun ca una a intestinului subţire de aceeaşi dimensiune şi cu acelaşi indice mitotic (8).

Totuşi, la un indie mitotic mare de peste $5 / 50$ câmpuri microscopice la aceleaşi dimensiuni tumorale, evoluţia progresivã a bolii este de $86 \%$ indiferent de localizare. Practic indexul mitotic este sugestiv pentru gradul de malignitate, cu precizarea că un indice scăzut nu certificã benignitatea leziunii (9). În cazul nostru activitatea mitoticã a fost absentă ceea sugera un prognostic bun al pacientului. $\mathrm{Cu}$ toate acestea dimensiunile mari ale tumorii şi localizarea intestinală constituiau factori de prognostic negativ.

Tratamentul de elecţie este chirurgical. Datele din literatură nu au demonstrat niciun beneficiu al rezecţiei extinse comparativ cu rezecţia limitată cu confirmarea histopatologică a lipsei invaziei lezionale la nivelul limitelor de secţiune (10), situaţie în care se încadrează şi cazul prezentat. În plus, sunt beneficiile conservării unei porţiuni cât mai extinse din intestin.

GIST nu diseminează pe cale limfatică, limfadenectomia de rutină neavând niciun beneficiu la aceşti pacienţi. Totuşi, diagnosticul fiind unul histopatologic şi imunhistochimic, este mai sigură evidarea ganglionară intraoperatorie (11).

Pentru prevenirea recidivelor tumorale şi în cazul diseminărilor metastatice se preferă administrarea postoperatorie de inhibitori de tirozinkinaze (imatinib-mesilat - Glivec) ca tratament adjuvant (12).

Pacientul prezintă un prognostic bun nefiind evidenţiate mitoze în secţiunile examinate. Dimensiunile mari ale tumorii însă sunt asociate cu risc crecut de malignitate.

Evoluţia nefavorabilă postoperatorie nu s-a datorat în principal formaţiunii tumorale, cât diagnosticului tardiv, probabil după mulţi ani de evoluţie, a anemiei şi malabsorbţiei asociate cu hipoproteinemie severă.

\section{Concluzii}

Orice anemie feriprivă este o urgență de diagnostic și nu de tratament. Trebuie investigată etiologic, terapia marţială fiind indicatã doar după elucidarea şi tratarea cauzei anemiei.

Sunt necesare investigaţii cu înaltă sensibilitate şi specificitate pentru explorarea unui sindrom anemic, tumorile intestinale putând fi omise la investigaţii uzuale.

Diagnosticul tumorilor stromale gastrointestinale este unul histopatologic şi imunhistochimic. Evoluțăa tumorilor stromale este cu atât mai bună cu cât diagnosticul este mai precoce.

\section{Disclosure:}

The authors have nothing to disclose.

\section{Funding:}

The authors declare no specific funding for this research from any funding agency in the public, commercial, or not-for-profit sectors.

\section{Competing interests:}

The authors declare none.

Patient consent:

The patient consent was obtained.

\section{Bibliografie}

1. Raut CP, Morgan JA, Ashley SW. Current issues in gastrointestinal stromal 
tumors: Incidence, molecular biology, and contemporary treatment of localized and advanced disease. Curr Opin Gastroenterol 2007;23:149-58.

2. Min KW, Leabu M. Interstitial cells of Cajal (ICC) and gastrointestinal stromal tumor (GIST): Facts, speculations, and myths. J Cell Mol Med 2006; 10:9951013.

3. Mazur MT, Clark HB. Gastric stromal tumors: Reappraisal of histogenesis. Am J Surg Patho l 1983; 7: 507-19.

4. Ducimetière F, Lurkin A, RanchereVince $\mathrm{D}$, et al. Incidence of sarcoma histotypes and molecular subtypes in a prospective epidemiological study with central pathology review and molecular testing. PLoS One 2011;6: e20294.

5. Barakat FH, Haddad HA, Matalka II, et al. Characteristics of gastrointestinal stromal tumors in a Middle Eastern population. Saudi Med J 2010; 31:797802.

6. Bucher P, Villiger P, Egger JF, Buhler LH, Morel P. Management of gastrointestinal stromal tumors: From diagnosis to treatment. Swiss Med Wkly 2004; 134:145-53.

7. Wong NA. Gastrointestinal stromal tumours - An update for histopathologists. Histopathology 2011; 59:807-21.

8. ESMO/European Sarcoma Network Working Group. Gastrointestinal stromal tumors: ESMO Clinical Practice Guidelines for diagnosis, treatment and follow-up. Ann Oncol 2014;23 Suppl 7: vii49-55.

9. Joensuu H, Vehtari A, Riihimäki J, et al. Risk of recurrence of gastrointestinal stromal tumor after surgery: an analysis of pooled population-based cohorts. Lancet Oncol. 2012; 13: 265-274.

10. Koh YX, Chok AY, Zheng HL, et al. A systematic review and meta-analysis comparing laparoscopic versus open gastric resections for gastrointestinal stromal tumors of the stomach. Ann Surg Oncol 2013; 20:3549-60.

11. Liang JW, Zheng ZC, Zhang JJ, et al. Laparoscopic versus open gastric resections for gastric gastrointestinal stromal tumors: A meta-analysis. Surg Laparosc Endosc Percutan Tech 2013; 23:378-87.

12. Joensuu H, Eriksson M, Sundby Hall K, et al. One vs three years of adjuvant imatinib for operable gastrointestinal stromal tumor: a randomized trial. JAMA. 2012; 307: 1265-1272 